\title{
Development of Excitation System Modelling Approaches for the Nigerian Grid
}

\author{
Mohamed Osman \\ and Gareth Taylor \\ Brunel University London \\ Uxbridge, Middlesex, UK
}

\author{
Barry Rawn \\ Carnegie Mellon University Africa \\ Kigali, Rwanda
}

\author{
Tochi Nwachukwu \\ New Mexico State University \\ Las Cruces, NM 88001
}

\begin{abstract}
The structure of the Nigerian interconnected system, which includes long power lines and a small number of generators, leads to technical challenges to stability of the interconnection. The static models of the Nigerian high voltage system indicate certain system deficiencies and weak points but records and observations of system collapses suggest that swing instabilities are sometimes part of rapid frequency decline. A dynamic model of system behavior can help determine whether system stability is major limiting factor for system operation, enable better forensic analysis of blackout events, lead to proposals for mitigating measures within the reach of operators. Accurate modelling of generator excitation systems represents a critical first step in the development of robust dynamic models- but validated excitation system parameters are not necessarily available for all generators, For when not all parameters are available, this paper establishes and tests a procedure that is used to select credible parameters. The paper demonstrates how one can an build acceptable power system model that supports preliminary benchmarking and validation.
\end{abstract}

Index Terms-- 1. Dynamic Modelling, Excitation System Tuning, Step Response Test

\section{INTRODUCTION}

The Nigerian power grid went through restructuring in the last decade with Electric Power Sector Reform Act enacted in 2005 to drive reform process and subsequently sector regulator (NERC) was established in October 2005. The restructuring also unbundled the Power Holding Company of Nigeria into Transmission Company of Nigeria (TCN), six generation companies and 11 distribution providers [1]. The grid is characterized by having a few high voltages (HV) transmissions lines that connect between the load centers, with a large amount of generation in the South and South-East. The system splits into two or more islands when critical lines are lost, and often collapses [5].

Load flow and dynamic studies are both fundamental to assess power system behavior under normal and stressed operation conditions. Load flow can aid the determination of maximum power transfer capacities and the risks of voltage collapse. However, stability has been the dominant factor that limits long-distance power transmission and requires accurate dynamic models. The traditional problem of first swing stability, which concerns having sufficient post fault synchronizing power had several solutions including use of high response excitation, but confirming this solution requires accurate generator models. In Nigeria, frequent total and partial system collapses are observed. Some collapses may have been due to severe power imbalance and may have been salvageable by under-frequency load shedding [1] partitioning the system into islands for later resynchronization. Other collapses may have been related to reactive power management and extreme high or low voltages. In both cases, an accurate dynamic representation of generators and loads is needed to evaluate collapse mechanisms and mitigations.

The paper is the first of several papers to address building the Nigerian Dynamic model from scratch. The Nigerian Planning Authority is using PSS/E [4] software tool from Siemens PTI and accordingly all the model building was done using this tool.

\section{TYPES OF EXCITATION SYSTEMS}

Synchronous machine excitation systems can be classified into three major groups based on the power supply used as source of excitation [8]. These are DC excitation, AC excitation and static excitation systems.

1) DC Excitation System: This excitation system utilizes DC generators as source of excitation power. It also provides current to the rotor of synchronous machine through slip rings. The exciter can be driven by a motor or shaft of a generator. It can be either self-excited or separately excited. When it is separately excited, the exciter field current is supplied by a pilot exciter comprising of a permanent magnet generator. DC excitation systems represent early systems, spanning the years from the 1920s to the 1960s. They lost favor in the mid-1960s and were superseded by ac excitation systems.

2) AC Excitation Systems: These excitation systems utilize alternators as source of generator excitation power. Usually, the exciter is kept on the same shaft as the turbine generator. The AC output of the exciter is rectified by either controlled or diode rectifiers to produce the direct current which is needed for the generator field. The rectifiers can be stationary or rotating. AC 
This article has been accepted for publication in a future issue of this conference proceedings, but has not been fully edited. Content may change prior to final publication. Citation information: DOI10.1109/UPEC50034.2021.9548257, 2021 56th International Universities Power Engineering Conference: Powering Net Zero Emissions, UPEC 2021 - Proceedings

excitation systems can take many forms depending on the rectifier arrangement, method of exciter output control, and source of excitation for the exciter. Currently, stationary, and rotating $\mathrm{AC}$ rectifier systems are widely used in $\mathrm{AC}$ excitation systems. In stationary rectifiers, the DC output is fed to the field winding of the generator through the slip rings. On the other hand, in rotating rectifiers there is no need of slip rings and brushes. The DC supply is directly fed to the generator field as the armature of the exciter and rectifiers rotate with the generator field. Such systems are known as brush-less systems and were developed to avoid the problems with brushes when extremely high field currents are applied to large generators [8].

3) Static (ST) Excitation Systems: All the components of these systems are either static or stationary. Such systems directly provide synchronous generator field winding with excitation current by means of slip rings. Rectifiers in ST systems gain the power from generator through auxiliary windings or a step-down transformer. In such systems, generator is a source of power which means that the generator is self-excited. As the generator cannot produce any voltage without excitation voltage, the generator must have an auxiliary power source to provide field current and energize the generator [2]. Station batteries are usually used as additional power sources and the process is known as field flashing. From the excitation power gain point of view the excitation systems can be further divided into independent and dependent excitation systems. The independent exciter is not connected to the grid. Thus, its excitation parameters have no direct relationship with grid parameters [2]. The dependent exciter utilizes either part of generator power or it is connected to the grid. Its excitation parameters are dependent on grid parameters.

\section{CONVENTIONAL DYNAMIC MODEL CONSTRUCTION}

The conventional method adopted in dynamic stability analyses is to perform time domain simulation on adequate mathematical models. The complete system is modeled with configuration of non-linear differential equations that describe the behavior of the individual system components.

All the machines connected to the high voltage network and represented in the Load Flow model are represented individually with appropriate data set that consists of following parts:

A. Generator data: Generator data relates to physical parameters of the generator, i.e., impedances, time constants, inertia, and saturation. Most manufacturer design parameters are close to values validated through field tests, so that manufacturer data is typically accurate enough for studies. As with all transient stability models, it is necessary to consider the range of operating conditions for which the models are valid. Almost all generators in the system are represented with two types of models from PSS/E [3] dynamic model library:

- $\quad$ GENSAL - salient pole dynamic model (hydro power plant)

- GENROU - round rotor dynamic model (thermal power plants turbo generators)

B. Excitation System data: Transient stability models include the excitation system, composed of the automatic voltage regulator (AVR), different limiters (frequency, excitation, current, etc.), a power system stabilizer (PSS), if active, and the exciter. A wide variety of excitation systems are used depending on the equipment producer and type for modeling. Generators within the Nigerian system were equipped with EXST1, IEEET2, IVOEX, and ESST4B [2].

C. Turbine and governor data: Turbine-governor controls may be included in a transient stability model, except for specific cases in which a unit may not provide governor response due to its design or operation. Hydro turbine and governors in the model are represented with IEEEG2, while gas fired thermal turbine by IVOGO and IEESGO, based on the provided consultant report [6].

D. Modeling of Rotating Loads: The complex load model (CLOD) replaces all constant MVA, current and admittance loads with a composite load consisting of induction motors, lighting, and other types of equipment such as would be fed from many typical substations. It is intended for use in situations where it is desirable to represents loads dynamically, rather than using the algebraic characteristic level used in load flow study. The model allows the user to specify a minimum amount of data stating the general character of the composite load. It then uses this data internally to establish the relative sizes of motors modeled in dynamic detail. The PSS/E [4] complex model

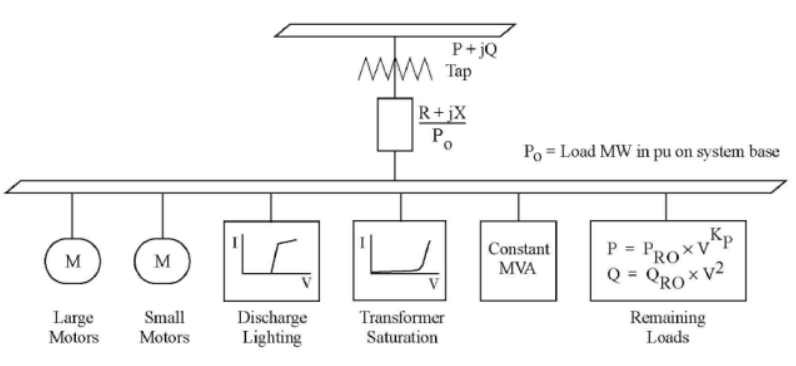

Figure 1: Complex Load Model (CLOD)

assume all load components are connected at 0.98 p.u. voltage. At initialization, a tap is calculated to obtain that voltage based on the load and voltage shown on the bus at which it is connected. The load on the bus is then split according to the percentage the user inputs.

When estimating fault levels in power systems of developing countries, both low and high fault levels should be considered. Evidence of high fault levels, which is a local problem for areas near generation, can be inferred from breaker failures. Upon too high a fault level, the circuit breaker will melt down or fail to operate. This can be a major problem and is often not considered in fault analysis. The following questions can be considered to anticipate high fault levels:

- Is the transmission/distribution model sufficiently accurate? 
This article has been accepted for publication in a future issue of this conference proceedings, but has not been fully edited. Content may change prior to final publication. Citation information: DOI10.1109/UPEC50034.2021.9548257, 2021 56th International Universities Power Engineering Conference: Powering Net Zero Emissions, UPEC 2021 - Proceedings

- Are the generator fault infeeds correct, reflecting actually connected generators?

- $\quad$ Are the breaker failure and trip capabilities correctly captured in the model?

- Should equipment deterioration under lack of maintenance over time be accounted for?

- Are accurate recordings available?

Failure to operate is also a prospect if the size of the current measured by relays is too low. In either case, the fault will remain on the system, giving local or global problems. The following questions can be considered to anticipate low fault levels:

- Are the minimum performance fault levels of protection known, and certain to result in actuation?

- $\quad$ Are is there anecdotal or documented evidence from operators regarding failure to clear the fault breaker/protection?

- $\quad$ Are protection settings designed for early removal of low-capability devices likely to overload remaining devices?

In general, the possibility of differing clearing times should be evaluated. For the sparse networks, the transmission company may overstate the clearing time requirements for new circuit breakers, to ease the design task and allow for future development. This can be a factor that eases stability problems. However, where the data is unreliable tolerances must be included in any calculation, and a worst case for the lowest capability devices way warrant consideration.

\section{MODELLING APPROACH FOR PARTIAL INFORMATION}

In the case of the Nigerian high voltage system, a static grid model with lines, transformers, and generating unit type and size information was available. A default source of generation information was a consultant's report performed in 2013 [6]. While that report provided excellent inventory of the generator, excitation system and governors for each power plant, no power system model using positive sequence tools was constructed from that effort. This paper is the first attempt to the author's knowledge to develop a complete and workable power system model that can be used for time-domain simulation and focuses on correct excitation system tuning as a foundational step.

Information about load composition can be partly inferred by information on the proportion of customer classes in distribution company areas.

\section{A. Selection of Load Models}

After examination of the load structure in Nigeria's 11 distribution system areas, the following four general types of loads are identified:

1) Residential

2) Commercial

3) Industrial

4) Mixed (combination of residential, commercial, and industrial)

All calculated and estimated data for residential, commercial, and mixed are summarized in Table 1

Table 1: Percentage of Load Composition for CLOD

\begin{tabular}{|c|c|c|c|c|c|c|}
\hline & $\begin{array}{c}\% \\
\text { Large } \\
\text { Motor }\end{array}$ & $\begin{array}{c}\% \\
\text { Small } \\
\text { Motor }\end{array}$ & $\begin{array}{c}\% \\
\text { Transformer } \\
\text { Exciting } \\
\text { Current }\end{array}$ & $\begin{array}{c}\% \\
\text { Discharge } \\
\text { Lighting }\end{array}$ & $\begin{array}{c}\% \\
\text { Constant } \\
\text { Power }\end{array}$ & $\begin{array}{c}\text { KP of } \\
\text { Remaining }\end{array}$ \\
\hline Residential & 0 & 60 & 3 & 10 & 7 & 1.25 \\
\hline Commercial & 5 & 40 & 3 & 10 & 7 & 1.25 \\
\hline Mixed & 20 & 30 & 3 & 10 & 7 & 1.25 \\
\hline
\end{tabular}

\section{B. Tuning of Excitation System}

A modern excitation control system includes several controls, limiting, and protective functions. Any given excitation system can include only some or all these functions, depending on the requirements of the specific application and the type of exciter.

The main control functions of the excitation system are voltage regulators, excitation system stabilizers, power system stabilizers, voltage sensing and load compensator, underexcitation limiters, over-excitation limiters, and volts-perhertz limiters. An AC voltage regulator is used to maintain generator stator voltage, which also helps to control the generator excitation voltage. DC voltage regulator is used to hold generator excitation voltage on constant level, and it is manually controlled. The regulator is mainly used during tests, start-ups and to cover the AC regulator outages.

The steps described in this section have been carried out on each excitation system, for all the generating units in the power stations Nigerian grid. Step response test conducted using the provided default parameters shows poor performance. This is depicted in Figure 2 for one of the units using the EXST1 excitation system. The response is sluggish and poorly damped as shown by looking at the generator terminal voltage $v_{\mathrm{t}}$ and generator main field voltage $E F D$ against a standard 5 second simulation time.

A systematic approach was therefore required to tune all the excitation systems in the model. Figure 3 shows the block diagram for EXST1, a potential source controlled-rectifier excitation system intended to represent all systems in which 
This article has been accepted for publication in a future issue of this conference proceedings, but has not been fully edited. Content may change prior to final publication. Citation information: DOI10.1109/UPEC50034.2021.9548257, 2021 56th International Universities Power Engineering Conference: Powering Net Zero Emissions, UPEC 2021 - Proceedings

excitation power is supplied through a transformer from the generator terminals (or the unit's auxiliary bus) and is regulated by a controlled rectifier. This is the standard implementation of IEEE Type ST1 excitation system [2]

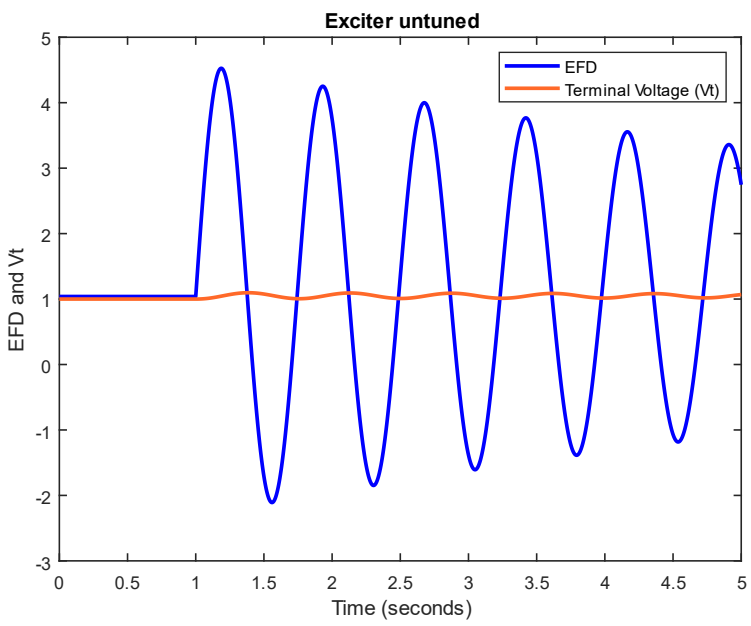

Figure 2: Step Response Test-Untuned Response

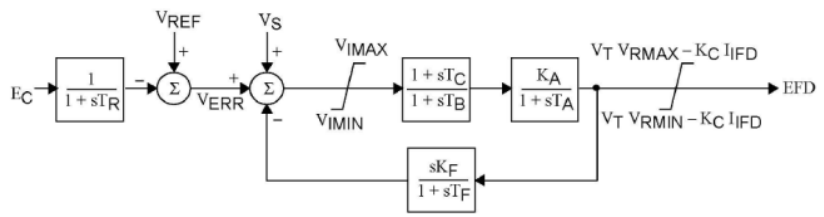

Figure 3: EXST1 Block Diagram

A common response test to conduct is the response to a stepin voltage reference with the machine on an open circuit. Koessler [3] recommended to emulate the same approach to the mathematical model. The EXST1 model shown represents transient gain reduction implemented either in the forward path (lead-lag block with time constants $\mathrm{T}_{\mathrm{B}}$ and $\mathrm{T}_{\mathrm{C}}$, in which case the feedback gain $\mathrm{K}_{\mathrm{F}}$ would normally be set to zero), or in the feedback path by suitable choice of rate feedback parameters $\mathrm{K}_{\mathrm{F}}$ and $\mathrm{T}_{\mathrm{F}}$ (in which case the lead-lag block should be ignored, by making $T_{B}$ and $T_{C}$ equal to zero), voltage regulator gain and time constant are represented by $\mathrm{K}_{\mathrm{A}}$ and $\mathrm{T}_{\mathrm{A}}$, respectively. For this tuning, the generator could be represented by the field open circuit time constant $\mathrm{T}_{\mathrm{do}}^{\prime}$. Here the transient gain $\mathrm{K}_{\mathrm{a}}$ is limited to:

$$
K_{a}<\frac{T_{d o}^{\prime}}{2 T_{A}}
$$

Here $\mathrm{T}_{\mathrm{do}}^{\prime}$ is 7.1 and $\mathrm{T}_{\mathrm{A}}$ is 0.01 with $\mathrm{K}_{\mathrm{a}}<355$,

$$
\text { say } K_{a} \text { is } 250
$$

Transient Gain reduction $(\mathrm{TGR})=\frac{K_{a}}{K_{A}}=\frac{250}{300}=0.83$

Choose $\mathrm{T}_{\mathrm{c}}=10 * \mathrm{~T}_{\mathrm{A}}=10 * 0.01=0.1$
$\mathrm{T}_{\mathrm{B}}=\frac{\mathrm{T}_{\mathrm{C}}}{\mathrm{TGR}}=\frac{0.1}{0.83}=0.12$

Note: 10 is chosen here such that $\frac{1}{T_{c}}$ is 10 times smaller than crossover frequency so that the actual gain seen by the voltage regulating loop will be the transient gain [3].

Following the procedure, the tuned parameter for a selected generator are summarized and shown in Table 2. Same process was repeated for other 130 generators that using different excitation system types like IEEET2, IVOEX and ESST4B [2]. Figure 4 displays representative eigenvalues of dominant states for each of the 130 generators before and after tuning [8]. Several units show their eigenvalues either in the imaginary axis or close to it, this indicates the oscillation was as expected. With proper tuning of excitation system for each generator for expected range of system operating conditions, all these eigenvalues will be moved to the left of the imaginary axis and generators will be damped appropriately.

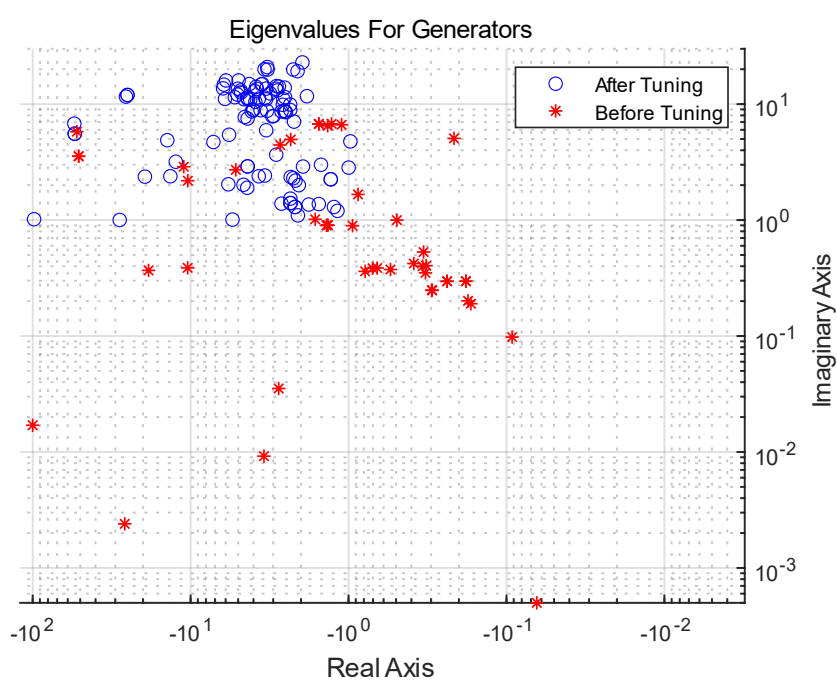

Figure 4: Representative Eigenvalues for each of the 130 Generators

Table 2: Original and Tuned parameters of EXST1 model

\begin{tabular}{|c|c|c|}
\hline & Provided Parameter & Tuned Parameter \\
\hline TR & 0.01 & 0.01 \\
\hline VIMAX & 0.102 & 0.102 \\
\hline VIMIN & -0.102 & -0.102 \\
\hline TC & 0.22 & $\mathbf{0 . 1}$ \\
\hline TB & 0.66 & $\mathbf{0 . 1 2}$ \\
\hline KA & 300 & 300 \\
\hline TA & 0.01 & 0.01 \\
\hline VRMAX & 6.3 & 6.3 \\
\hline VRMIN & -4.4 & -4.4 \\
\hline KC & 0.0 & 0.0 \\
\hline KF & 0.1 & $\mathbf{0}$ \\
\hline
\end{tabular}


This article has been accepted for publication in a future issue of this conference proceedings, but has not been fully edited. Content may change prior to final publication. Citation information: DOI10.1109/UPEC50034.2021.9548257, 2021 56th International Universities Power Engineering Conference: Powering Net Zero Emissions, UPEC 2021 - Proceedings

\begin{tabular}{|l|l|l|}
\hline TF & 1 & 1 \\
\hline
\end{tabular}

Figure 5 displays the open-circuit step response when the tuned parameters values are used. The response is well damped and reasonably fast, as compared to the response shown in Figure 2 before it was tuned.

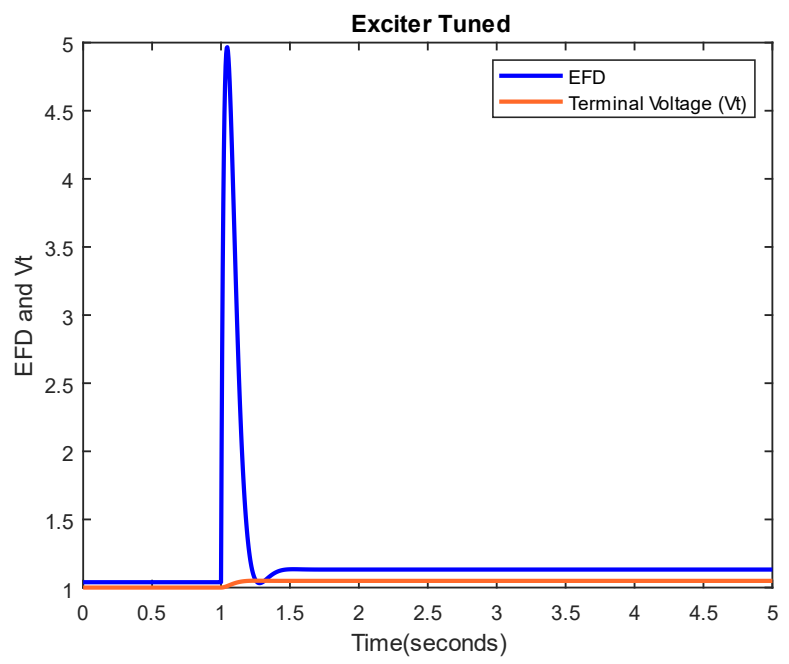

Figure 5: Step Response Test-Tuned Response

\section{TESTING AND VALIDATION}

An initial no fault simulation shows that the initialization problems that manifested as varying quantities without switching action, were the result of inconsistencies between the generating unit's output, MVA base, Pmax and the governor model limits. In some instances, unreasonably high/low reactive power output was observed. The field voltage of several generators caused their exciters to exceed the ceiling values. Then, the model limits were adjusted, or the power flow was modified to rectify the initialization problems. The development of the dynamic case was concluded with 20 seconds no-disturbance simulations as shown in Figure 6 which was plot up to 5 seconds for improving graph clarity.

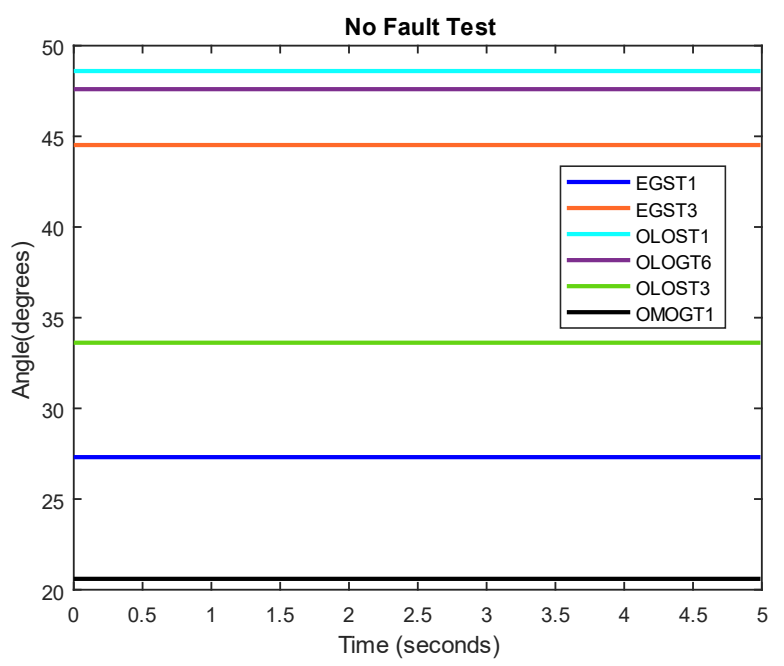

Figure 6: No Fault Simulation

\section{CONCLUSION AND FUTURE WORK}

It is critical to have the correct representation of elements of the power system and particularly the dynamic behavior of the generators and their controllers (governors and excitation systems). This paper presents systematic way of data checking and modifying control parameters in excitation systems to obtain credible simulation. EXST1 models and tuning were found to be appropriate for the Nigerian grid, and the same procedure could be applied to other types of excitation system.

Next steps of the dynamic model creation process are validating the developed model against actual events. To further analyze system responses, it is necessary to investigate system response to disturbances that cause large and sudden changes in the power system. Dynamic stability is a known concern for the Nigerian system, and a measurement campaign to monitor a major generating unit near the load center of Lagos could lead to the capture of relevant events. With a valid dynamic model, steps can be made to mitigate system stability as a major limiting factor for operation of the Nigerian high voltage system.

\section{REFERENCES}

[1] M. Osman, B. Rawn and T. Nwachukwu, "Analysis of Automatic Defence Options for Nigeria: June 27th 2017 Blackout," 2018 North American Power Symposium (NAPS), Fargo, ND, 2018, pp. 1-5, doi: 10.1109/NAPS.2018.8600664.

[2] IEEE Recommended Practice for Excitation System Models for Power System Stability Studies," in IEEE Std 421.5-2016 (Revision of IEEE Std 421.5-2005), vol., no., pp.1-207, 26 Aug. 2016, doi: 10.1109/IEEESTD.2016.7553421.

[3] Koessler, R. J., "Techniques for tuning excitation system parameters," IEEE Transactions on Energy Conversion, vol. 3, no. 4, pp. 785, 791, Dec. 1988.

[4] PSS/E Version 33 Manual, Siemens PTI, Schenectady, NY. 
This article has been accepted for publication in a future issue of this conference proceedings, but has not been fully edited. Content may change prior to final publication. Citation information: DOI10.1109/UPEC50034.2021.9548257, 2021 56th International Universities Power Engineering Conference: Powering Net Zero Emissions, UPEC 2021 - Proceedings

[5] I. Adaji, A. L. G. Raji and J. Tsado, "Prevention of voltage collapse on the Nigerian $330 \mathrm{kV}$ grid network using underfrequency load shedding scheme," 2017 IEEE PES PowerAfrica, Accra, 2017, pp. 533-537. doi: 10.1109/PowerAfrica.2017.7991282

[6] Report on Data Collection and Network Modelling, Jiyoda Engineering Nigeria Ltd, Lagos, Nigeria, October 2013

[7] Vanfretti, Luigi and Aliyu, Usman and Chow, Joe H; "Modelling of a System Collapse in the Nigerian National Power System using Frequency Disturbance Recorder Data", 9th International Conference on Power System Operations and Planning (ICPSOP) January 16th-19th, 2012, Nairobi, Kenya; pages 1-6, 2012

[8] P. Kundur, Power System Stability and Control. McGraw-Hill, 1994.

[9] Nigerian Electricity Regulatory Commission," THE GRID CODE FOR THE NIGERIA ELECTRICITY TRANSMISSION SYSTEM", retrieved Nov 1st, 2017 from http://www.nercng.org/

[10] IEEE Guide for Synchronous Generator Modelling Practices in Stability Analyses, IEEE Std 1110-1991, pp. 1-, 1991.

[11] IEEE Recommended Practice for Excitation System Models for Power System Stability Studies," IEEE Std 421.5-1992

[12] IEEE Recommended Practice for Excitation System Models for Power System Stability Studies," IEEE Std 421.5-2005

[13] K. Kim and R. C. Schaefer, "Tuning a PID controller for a digital excitation control system," IEEE Trans. Ind. Appl., vol. 41, no. 2, pp. 485492, Mar./Apr. 2005

[14] S. Ayasun and A. Gelen, "Stability analysis of a generator excitation control system with time delays," Elect. Eng., vol. 91, no. 6 , pp. 347355 , Jan. 2010.

[15] Z.-L. Gaing, "A particle swarm optimization approach for optimum design of PID controller in AVR system," IEEE Trans. Energy Convers., vol. 19, no. 2, pp. 384391, Jun. 2004.

[16] A. Godhwani, M. J. Basler, K. Kim and T. W. Eberly, "Commissioning experience with a modern digital excitation system," in IEEE Transactions on Energy Conversion, vol. 13, no. 2, pp. 183-187, Jun 1998.

[17] R. C. Schaefer, "Steam turbine generator excitation system modernization," in Proc. IEEE Pulp and Paper Industry Tech. Conf., 1995, pp. 194-204

[18] R. C. Schaefer, "Application of static excitation systems for rotating exciter replacement," in Proc. IEEE Pulp and Paper Industry Tech. Conf., 1997, pp. 199-208.

[19] A. Godhwani, M. J. Basler. "A Digital Excitation Control System for Use on Brushless Excited Synchronous Generators" IEEE Transactions on Energy Conversion, Vol. 11, No. 3, September 1996 